\title{
The Effects of the COVID-19 Pandemic on the Psychology of the Pharmacy School Stakeholders in Türkiye
}

\author{
(1) Muammer ÇALIKUȘU*, (1) Gülbin ÖZÇELIKAY \\ Ankara University, Faculty of Pharmacy, Department of Pharmacy Management, Ankara, Türkiye
}

\begin{abstract}
Objectives: The state of anxiety seen during the coronavirus disease-2019 (COVID-19) pandemic needs to be evaluated and controlled. Studies indicate that high anxiety reduces students' academic performance. The productivity and scientific studies of academicians have also been negatively affected during the pandemic. Psychological conditions of students and academicians need to be improved as high anxiety levels can affect academic achievement. In this study, the effects on psychological well-being (PWB) of COVID-19 anxiety levels of students and academicians in pharmacy schools in Türkiye have been determined.

Materials and Methods: This research was quantitative. As a data collection tool in the research, a questionnaire consisting of three parts was applied to the academic staff and students of pharmacy schools. After the first part of the questionnaire that aimed to determine general information, there were questions about the pandemic anxiety (PA) and the PWB scales. The universe of the study consists of 1.563 academic staff working in pharmacy schools and 17.101 students in these faculties. The level of significance $(\alpha)$ was determined as 0.05 in the analysis made in the study.

Results: Two hundred fortyseven academicians and 1.698 students participated in the research. Data was analyzed by SPSS ver. 25.0 program. $79 \%$ of the academic staff participating in the study were women, while $21 \%$ were men; for students, it was $77 \%$ and $23 \%$, respectively. Female academicians found to have significantly higher $(p=0.001)$ PA level than males. Female students had significantly higher levels of PA $(p=0.000)$ and PWB ( $p=0.027$ ) compared to male students.

Conclusion: In the study, PA of academicians was generally lower than students, while PWB was higher. When the relationship between PA and PWB was examined, the relationship between PA and PWB of the academicians was very low and positive; for the students, it was found to be very low and negative.
\end{abstract}

Key words: COVID-19 pandemic, pandemic anxiety, psychological well-being, pharmacy schools

\section{INTRODUCTION}

Fear appears as a reactive emotional state to perceptions of real or potential threat associated with autonomic arousal fluctuations, thoughts about immediate danger, and escape actions. Anxiety accompanies fear, when attempts to deal with a threat are unsuccessful; these two emotions are often experienced together.

The coronavirus disease-2019 (COVID-19) pandemic has become an important problem worldwide since December 2019. The pandemic has affected people of all nationalities, continents, races, and socio-economic groups. Measures such as quarantine of human populations around the world in different ways, closing of schools, transition to distance education, social isolation and curfews have suddenly changed daily lives. ${ }^{2}$ As a result, the pandemic has caused states of anxiety such as threats, fear, stress, anxiety, sadness, feeling lonely or anger. ${ }^{3,4}$ People's mental health is seriously affected because of social distancing measures. ${ }^{5}$ Stigmatization, fear of death, the uncertainty of the course of the disease, and immunological complaints are among the causes of anxiety in 
COVID-19 patients. ${ }^{6,7}$ A sudden decrease in social contact can have negative psychological consequences, as forced isolation disrupts the social nature of the human being. This can be seen with the development of severe psychological symptoms, such as increased anxiety, depression, and other psychotic affective disorders. $^{8}$

Psychological well-being (PWB) is generally defined as experiencing more positive emotions and less negative emotions. ${ }^{9}$ When the literature is examined, different definitions also stand out. Kammann and Flett ${ }^{10}$ expressed PWB as "a cognitive process of life satisfaction". Martin and Rubin ${ }^{11}$ drew attention to the link between physical health and a high quality of life. Consequentially, PWB is a concept that includes emotional, physical, cognitive, spiritual, and social processes. ${ }^{12}$

In this study, the effects on PWB of the COVID-19 anxiety levels of students and academicians in pharmacy schools in Türkiye have been determined.

\section{MATERIALS AND METHODS}

The study is a screening research and quantitative. Scanning model is a study that collects data to determine certain characteristics of the group to be studied. ${ }^{13}$ As a data collection tool in the research, a questionnaire consisting of three parts was applied to the academic staff and students of pharmacy schools. After the first part of the questionnaire that aimed to determine general information, there were questions about the pandemic anxiety (PA) scale and the PWB scale..$^{14,15}$

The universe of the study consists of 1.563 academic staff working in pharmacy schools and 17.101 students in these faculties. ${ }^{16,17}$ Two hunred fourty-seven academicians and 1.698 students participated in the research. The data of 7 academic staff, who participated in the study, were excluded from the analysis due to incomplete information. The questionnaire was delivered via the internet by asking volunteers to participate in the study.

Before starting the survey application, ethical permission was obtained from the Ethics Committee of Ankara University (dated: 12/04/2021, decision number: 06/61) and the Scientific Research Platform of the Republic of Türkiye Ministry of Health. Following the approval of the ethics committee, research data were collected between 12/04-02/05/2021.

\section{Statistical analysis}

The research data were evaluated using SPSS 25.0. The normal distribution assumption was confirmed with KolmogorovSmirnov test and it was seen that the data displayed a normal distribution. The descriptive data of the research were evaluated with numbers and percentages. Independent samples $t$-test, paired-samples $t$-test, and one-way ANOVA were used for continuous data. A $p$ value of 0.05 or less in all tests was considered significant. The Cronbach-alpha reliability coefficient for the scales used in the research was calculated separately for academicians and students. The Cronbachalpha reliability coefficient for the PA scale was 0.840 for the academicians and 0.793 for the students; PWB scale was found to be 0.838 for academicians and 0.899 for students.

\section{RESULTS}

COVID-19 anxiety and PWB of academicians and students of pharmacy schools in Türkiye were evaluated with scales, and the results obtained are given below. Demographic information of the participants is shown in Table 1.

From Table 1, it is seen that $79 \%$ of academicians participating in the study are women, while $21 \%$ are men; in terms of academic titles, research assistants with $32.5 \%$ the highest participation, lecturers with lowest $2.5 \%$; in terms of age groups, approximately $40 \%$ of the participants between the ages of 31 40 , considering other age groups, each had approximately $20 \%$. We observed that lowest participation in terms of professional seniority is $16-20(10 \%)$ and $11-15(13.3 \%)$, respectively, and the other groups are around $25 \%$. The married participants were $60.4 \%$; approximately $50 \%$ of them were parents, and $24.2 \%$ of their closest family members (such as mother, father, and spouse) had COVID-19 disease.

In this study, $77 \%$ of the students were women, while $23 \%$ were men; in terms of year at the faculty, the highest attendance was in the $1^{\text {st }}$ year $(27.7 \%)$ and the lowest in the $5^{\text {th }}$ year $(9.3 \%)$. In the grouping made by age, it is seen that there is a balanced distribution, although there is relatively less participation at the age of 23 and above. $28.8 \%$ of the students stated that their relatives (such as mother, father, sibling) had COVID-19 disease, and $7.5 \%$ stated that they had a chronic disease.

\section{Normality tests}

To verify the study, the data collected must conform to a normal distribution. Compliance of data with a normal distribution is determined by the test of normality. ${ }^{18}$ The normality test of the data in this study was carried out with the SPSS ver 25.0 package program. The normality test consists of three stages. ${ }^{19}$ In the first stage, the data were examined formally. In the second stage, we checked whether the skewness and kurtosis values of the data were within acceptable ranges. Finally, in the third stage, the data were analyzed with Kolmogorov-Smirnov test.

In the formal examination, which is the first step of the normality test, the minimum and maximum values, average values, frequency, and standard deviation values of the data were calculated, which are displayed in Table 2.

The data collected in the second stage of the normality test were analyzed in terms of skewness and kurtosis values. These values are important in terms of demonstrating how the available data are positioned on the normal distribution curve. This positioning is a guide to check whether the data conform to the normal distribution. The statistical value range for the $5 \%$ confidence interval of skewness and kurtosis is expected to be \pm 2.58 , and for the $1 \%$ confidence interval the statistical value range is expected to be $\pm 1.96 . .^{20}$ The skewness and kurtosis values of the research data are given in Table 2. When the results of the skewness and kurtosis tests are examined, it is seen that the data obtained from the PA and PWB scales applied to academicians and students are within $5 \%$ confidence interval. 
The final stage of the normality test is Kolmogorov-Smirnov test. In this test, the degree of agreement between the distribution of sample data and the theoretical distribution is examined. The significance level of Kolmogorov-Smirnov test's result value is above 0.05 reveals that the data are suitable for distribution. From the test results, it was determined that all data was significant.

\section{Comparison of academicians and students' data}

In Table 3, the responses of academicians and students to the PA and PWB scales are generally compared. As it can be understood from Table 3, pandemic anxieties of academicians are generally lower and their PWB is higher than students. On the PA scale, students stated that they agreed at a higher level compared to the academicians to the statements "Sometimes, I have the feeling that the coronavirus will never end.", "I think, I will not get good health care in case of coronavirus transmission." and "I worry about the curfew/prolongation of the ban." On the PWB scale, the academicians stated that they agree more with the statements "I live a purposeful and meaningful life.", "My social environment supports and rewards me." and "I am optimistic about my future."

Table 2. Descriptive statistics of research data

\begin{tabular}{lllllllll} 
& Standard error average & SD & Variance & Minimum & Maximum & Average & Skewness & Kurtosis \\
\hline PA students & 0.027 & 1.090 & 1.189 & 1.00 & 7.00 & 5.1540 & -0.905 & 1.029 \\
\hline PWB students & 0.028 & 1.142 & 1.305 & 0.89 & 6.22 & 4.2623 & -0.823 & 0.334 \\
\hline PA academicians & 0.072 & 1.119 & 1.252 & 1.67 & 7.00 & 4.738 & -0.265 & -0.583 \\
\hline PWB academicians & 0.039 & 0.614 & 0.377 & 3.11 & 6.22 & 5.014 & -0.443 & -0.031 \\
\hline
\end{tabular}

PA: Pandemic anxiety, PWB: Psychological well-being, SD: Standard deviation

Table 3. Responses of academicians and students to PA and PWB scales

\begin{tabular}{|c|c|c|c|c|}
\hline Pandemic anxiety & \multicolumn{2}{|c|}{ Academicians } & \multicolumn{2}{|l|}{ Students } \\
\hline 1- I am worried about getting coronavirus. & 5.28 & 1.674 & 5.28 & 1.798 \\
\hline 3- Sometimes I have the feeling that the coronavirus will never end. & 4.75 & 1.710 & 5.43 & 1.679 \\
\hline 4- I think I will not be able to get good health care in case of coronavirus transmission. & 3.75 & 1.777 & 4.41 & 1.858 \\
\hline 6- Due to the coronavirus. I cannot continue my social life as before. & 5.93 & 1.325 & 6.24 & 1.364 \\
\hline 7- The idea of not being able to access equipment such as masks worries me. & 3.14 & 1.886 & 3.61 & 2.014 \\
\hline 8- The negative news in the media (visual, written, social) about coronavirus worries me. & 4.50 & 1.795 & 4.96 & 1.918 \\
\hline 1- I live a purposeful and meaningful life. & 5.68 & 1.083 & 3.98 & 1.983 \\
\hline 2- My social environment supports and rewards me. & 5.62 & 0.995 & 4.64 & 1.727 \\
\hline 3- I participate in activities that I am responsible and love in my daily life. & 5.38 & 1.186 & 4.73 & 1.730 \\
\hline 4- I actively contribute to the happiness and well-being of others. & 5.78 & 0.842 & 5.35 & 1.454 \\
\hline 5- I am competent and talented in activities that are important to me. & 5.75 & 0.900 & 5.04 & 1.541 \\
\hline 6- I am a good person and living a good life. & 5.87 & 0.831 & 5.15 & 1.528 \\
\hline 7- I am optimistic about my future. & 5.28 & 1.275 & 4.19 & 1.907 \\
\hline 8- People respect me. & 5.78 & 0.861 & 5.28 & 1.468 \\
\hline
\end{tabular}

SD: Standard deviation, PA: Pandemic anxiety, PWB: Psychological well-being 
The total scores of academicians and students from the PA and PWB scales are compared with each other and by gender with the independent two-sample $t$-test.

According to the test results displayed in Table 4, academicians have statistically significantly lower PA levels yet higher PWB levels than students in terms of gender and total scale scores.

\section{Findings of academicians}

Since it was determined that the data conformed to the normal distribution in the data analysis by academicians and students, independent two-sample $t$-test was used to compare two independent groups, and ANOVA test was used to determine the differences between the means of three or more independent groups.

\section{Independent two-sample t-test results}

Table 5 shows the results of two independent samples $t$-test on the gender, marital status, parenting status, and COVID-19 sight status in nearby (spouse, mother, father, etc.) of the academicians.

As can be seen from Table 5;

- Female academicians have a significantly higher $(p=0.001)$ PA level than male academicians.

- Married academicians have a significantly higher $(p=0.039)$ PA level than single academicians.

- Academicians with COVID-19 sight status nearby have a significantly higher ( $p=0.006)$ PWB level than those who do not.

- There was no significant difference between the parenting status of the instructors of PA and PWB levels.

\section{ANOVA test results}

The results of the ANOVA test regarding the age, academic title, and professional seniority of the academicians are presented in Table 6. According to the test results, there was no significant difference between the groups ( $p>0.05$ ).

Correlation analysis was conducted to measure the effect of the PA of the lecturers on their PWB; a positive but very low correlation (Pearson correlation coefficient: 0.027) was found.

\section{Findings of students}

\section{Independent two-sample t-test results}

Table 7 shows the results of independent two-sample $t$-test on students' gender, chronic disease, and COVID-19 sight status nearby (mother, father etc.).

As can be seen from Table 7;

- Female students had significantly higher PA ( $p=0.000)$ and PWB ( $p=0.027$ ) levels compared to male students.

- There was no significant difference between the levels of PA and PWB of the chronic disease status and COVID-19 sight status in nearby.

\section{ANOVA test results}

The results of ANOVA test for age of the students and the year in the school are revealed in Table 8.

According to the test results;

- There was no significant difference between the ages of the students and their PA and PWB levels.

- While there is no significant relationship between students' years at the school and their PA levels, a significant difference existed among their PWB levels. Students in the

Table 4. Independent two-sample $t$-test results of academicians and students by gender and total scale scores

\begin{tabular}{|c|c|c|c|c|c|}
\hline Female & & $\mathrm{n}$ & Mean & SD & Significance (2 tailed) \\
\hline \multirow{2}{*}{ PA } & Students & 1306 & 47.4786 & 9.18753 & \multirow{2}{*}{0.000} \\
\hline & Academicians & 189 & 43.7302 & 9.68856 & \\
\hline \multirow{2}{*}{ PWB } & Students & 1306 & 38.6639 & 10.08141 & \multirow{2}{*}{0.000} \\
\hline & Academicians & 189 & 45.2646 & 5.40723 & \\
\hline PA & Academicians & 51 & 38.5882 & 10.50748 & 0.010 \\
\hline \multirow{2}{*}{ PWB } & Students & 392 & 37.3520 & 10.87448 & \multirow{2}{*}{0.000} \\
\hline & Academicians & 51 & 44.6275 & 5.97314 & \\
\hline \multicolumn{6}{|l|}{ Total } \\
\hline \multirow{2}{*}{ PWB } & Students & 1698 & 38.3610 & 10.28153 & \multirow{2}{*}{0.000} \\
\hline & Academicians & 240 & 45.1292 & 5.52552 & \\
\hline
\end{tabular}

SD: Standard deviation, PA: Pandemic anxiety, PWB: Psychological well-being 
Table 5. Independent two-sample t-test results of academicians regarding gender, marital status, parenting status, and COVID-19 sight status in nearby

\begin{tabular}{|c|c|c|c|c|c|}
\hline Gender & & $\mathrm{n}$ & Mean & SD & Sig. (2 tailed) \\
\hline \multirow{2}{*}{ PA } & Female & 189 & 43.730 & 9.689 & \multirow{2}{*}{0.001} \\
\hline & Male & 51 & 38.588 & 10.508 & \\
\hline \multirow{2}{*}{ PWB } & Female & 189 & 45.265 & 5.407 & \multirow{2}{*}{0.466} \\
\hline & Male & 51 & 44.628 & 5.973 & \\
\hline \multicolumn{6}{|c|}{ Marital status } \\
\hline \multirow{2}{*}{ PA } & Married & 145 & 43.724 & 10.287 & \multirow{2}{*}{0.039} \\
\hline & Single & 95 & 40.979 & 9.543 & \\
\hline \multirow{2}{*}{ PWB } & Married & 145 & 45.221 & 5.230 & \multirow{2}{*}{0.752} \\
\hline & Single & 95 & 44.990 & 5.974 & \\
\hline \multicolumn{6}{|c|}{ Parenting status } \\
\hline \multirow{2}{*}{ PA } & Yes & 119 & 42.966 & 11.005 & \multirow{2}{*}{0.617} \\
\hline & No & 121 & 42.314 & 9.089 & \\
\hline \multirow{2}{*}{ PWB } & Yes & 119 & 45.445 & 5.179 & \multirow[t]{2}{*}{0.380} \\
\hline & No & 121 & 44.818 & 5.851 & \\
\hline \multicolumn{6}{|c|}{ COVID-19 sight status in nearby } \\
\hline \multirow{2}{*}{ PA } & Yes & 58 & 40.848 & 11.383 & \multirow[t]{2}{*}{0.120} \\
\hline & No & 182 & 43.209 & 9.576 & \\
\hline \multirow{2}{*}{ PWB } & Yes & 58 & 46.845 & 4.793 & \multirow[t]{2}{*}{0.006} \\
\hline & No & 182 & 44.582 & 5.642 & \\
\hline
\end{tabular}

SD: Standard deviation, PA: Pandemic anxiety, PWB: Psychological well-being, COVID-19: Coronavirus disease-2019, Sig: Significance

Table 6. ANOVA test results regarding age, title and professional seniority of academicians

\begin{tabular}{llll} 
& Age & Title & Seniority \\
\hline & Significance & & \\
\hline PA & 0.277 & 0.118 & 0.628 \\
\hline PWB & 0.992 & 0.739 & 0.958 \\
\hline
\end{tabular}

PA: Pandemic anxiety, PWB: Psychological well-being

$1^{\text {st }}$ year have a significantly higher level of PWB than those in the $2^{\text {nd }}$ year, and the students in the $5^{\text {th }}$ year compared to students in the $3^{\text {rd }}$ and $4^{\text {th }}$ years.

Finally, correlation analysis was conducted to measure the effect of PA of students on their PWB; a very weak and negative relationship (Pearson correlation coefficient: -0.068) was determined.

\section{DISCUSSION AND CONCLUSION}

In this study, the effects of the anxiety created by the COVID-19 pandemic on PWB of academicians and students in pharmacy schools in Türkiye were determined.

The sudden emergence of COVID-19 virus and the occurrence of a pandemic in a very short time have caused the emergence of situations that affect people's anxiety and PWB. It can be seen that there are many studies on the effect of COVID-19 on human psychology. ${ }^{21-25}$ The effects of the pandemic on human psychology have emerged because of the changes and restrictions in the lives of people around the world.

In this study, it was found that academicians generally had lower PA and higher PWB than students. In the literature, the results supporting the fact that PA is lower among the academic staff than in the students have been determined. In a study conducted in England, the mental health of society was examined in the COVID-19 pandemic and the level of anxiety was found to be higher at younger ages. ${ }^{26}$ In another study, Joos ${ }^{27}$ examined the psychological variables experienced by individuals during the COVID-19 pandemic and found that the anxiety levels of individuals aged 20-30 were higher than those of other ages. In a study investigating the effects of fear and anxiety of COVID-19 on psychological distress, sleep disturbance, and life satisfaction in university students in Vietnam, it was found that fear and anxiety of COVID-19 were positively associated with psychological distress. It has been determined that sleep disorder also positively affects COVID-19 fear and anxiety.28 Similarly, a study conducted in Italy revealed that COVID-19 seems to be a risk factor for sleep disorders and psychological diseases. $^{29}$

In a study conducted in Iran, the problems faced by academicians during the COVID-19 pandemic period were examined into two 
Table 7. Independent two-sample $t$-test results of students on gender, chronic disease, and COVID-19 sight status in nearby

\begin{tabular}{|c|c|c|c|c|c|}
\hline Gender & & $\mathrm{n}$ & Mean & SD & Significance (2 tailed) \\
\hline \multirow{2}{*}{ PA } & Female & 1306 & 47.479 & 9.188 & \multirow{2}{*}{0.000} \\
\hline & Male & 392 & 42.747 & 10.913 & \\
\hline \multirow{2}{*}{ PWB } & Female & 1306 & 38.664 & 10.081 & \multirow{2}{*}{0.027} \\
\hline & Male & 392 & 37.352 & 10.875 & \\
\hline PA & No & 1570 & 46.326 & 9.765 & 0.376 \\
\hline \multirow{2}{*}{ PWB } & Yes & 128 & 38.523 & 9.7901 & \multirow[t]{2}{*}{0.853} \\
\hline & No & 1570 & 38.348 & 10.323 & \\
\hline \multirow{2}{*}{ PWB } & Yes & 489 & 38.344 & 10.229 & \multirow[t]{2}{*}{0.965} \\
\hline & No & 1209 & 38.368 & 10.307 & \\
\hline
\end{tabular}

SD: Standard deviation, PA: Pandemic anxiety, PWB: Psychological well-being, COVID-19: Coronavirus disease-2019

Table 8. ANOVA test results regarding age of students and year in school

\begin{tabular}{lcc} 
& Age & Year in school \\
\hline & & Significance \\
\hline PA & 0.251 & 0.262 \\
\hline PWB & 0.271 & 0.000 \\
\hline
\end{tabular}

PA: Pandemic anxiety, PWB: Psychological well-being

groups as those related to university and family. In a study conducted with academicians at Hamadan University of Medical Sciences, it was determined that the most prominent effect of COVID-19 was mental fatigue. ${ }^{30}$

When the total scores obtained from the scales were examined in the study, it was found that female students had a higher PA than female academicians and male students had a higher PA than male academicians. However, the opposite findings were obtained at PWB levels. It is thought that this situation is due to the increase in experience and knowledge gained with age.

Studies have shown that women have higher anxiety levels than men during the pandemic period. ${ }^{31}$ In a study conducted in the Philippines, it was found that the levels of stress, anxiety, and depression caused by the pandemic were higher in women. In the same study, it was revealed that single and childless individuals had significantly higher levels of stress, anxiety and depression. ${ }^{32}$

The productivity and scientific research of female academicians have been adversely affected by the pandemic.33-37 It was also determined in our study that female academicians had a significantly higher ( $p=0.001)$ PA level than male academicians.
It can be said that this result is compatible to some extent with previous studies showing that women are more prone to mental disorders. 38,39

In our study, no significant difference was found between the parenting status of the academicians and the levels of PA and PWB. Studies conducted in China and Vietnam have indicated that having children can be significantly associated with mental health problems such as stress, anxiety, and symptoms of depression. ${ }^{40,41}$ In a study conducted in Italy, $17 \%$ of the participants was observed to suffer severely from fatigue related to their parenting roles, especially during the measures taken by mothers due to the COVID-19 outbreak. ${ }^{42}$

In our study, there was no significant relationship between students' years at the school and their PA levels, but a significant difference was found between their PWB levels. Students in the $1^{\text {st }}$ year have a significantly higher level of PWB than those in the $2^{\text {nd }}$ year, and the students in the $5^{\text {th }}$ year compared to with students in the $3^{\text {rd }}$ and $4^{\text {th }}$ years. A study conducted in the United States indicated that students in the higher classes had higher levels of anxiety. ${ }^{43}$ In a study conducted to evaluate the level of anxiety among university students in Sudan, $75 \%$ of the students were found to have a low level of anxiety. The results of the same study in Nigeria found that more students experienced moderate to severe anxiety during the pandemic. ${ }^{31}$ In a similar study conducted in China, it was determined that students with moderate and severe anxiety levels had a higher rate. ${ }^{44}$ In a study conducted in India, it was stated that students' anxiety levels increased more than that of other groups participating in the study during restrictions. ${ }^{45}$ Another study conducted in Argentina revealed that being a student causes high psychological distress during quarantine. ${ }^{46}$ 
Many studies have used broad socio-demographic factors, such as education, age, marital and parenting status, experiences, having children, professional achievements, and health problems, to explain differences in PWB. These experiences vary according to their position in the life course and the nature of the challenge or task posed. ${ }^{47}$ Ryff and Keyes ${ }^{48}$ found in their study that women scored significantly higher than men on positive relationships and personal growth. Numerous studies have revealed that family and especially marriage has a decisive impact on life satisfaction, PWB, and mental and physical health. Young children and adolescents, who are given love, acceptance, and support by their parents, have higher selfesteem, lower anxiety, and depression levels, more happiness and success, and less behavioral problems. ${ }^{49}$

As a result, the COVID-19 pandemic has affected people of all age groups, although it has occurred to varying degrees. The possibility of getting sick and the uncertainty of the process can cause anxiety and thus a decrease in PWB levels. In this study, PA level among students was higher, but PWB was found to be higher among the academicians in pharmacy schools in Türkiye. This situation may be associated with a higher level of consciousness among the academicians. To increase the PWB of academicians and students during the pandemic process;

- Disclosures made through official authorities should include anxiety-relieving messages, rather than just negative data.

- Accessibility to medical resources and health services should be further developed and improved.

- Digital resources used in distance education should be developed and students' access to course materials should be facilitated.

- Scholarships can be provided to students whose financial situation has deteriorated due to the pandemic.

It is thought that any kind of social support that will be provided in this way will not only reduce the psychological pressure, but will also facilitate the function of seeking help.

Ethics

Ethics Committee Approval: Ethics Committee of Ankara University (dated: 12/04/2021, decision number: 06/61) and the Scientific Research Platform of the Republic of Turkey Ministry of Health.

Informed Consent: Informed consent forms have been obtained from all volunteers.

Peer-review: Externally peer-reviewed.

\section{Authorship Contributions}

Concept: M.Ç., G.Ö., Design: M.Ç., G.Ö., Data Collection or Processing: M.Ç., G.Ö., Analysis or Interpretation: M.Ç., G.Ö., Literature Search: M.Ç., G.Ö., Writing: M.Ç., G.Ö.

Conflict of Interest: No conflict of interest was declared by the authors.

Financial Disclosure: The authors declared that this study received no financial support.

\section{REFERENCES}

1. Kalat J, Shiota M. Emotion: Classification of Emotions. Thomson Wadsworth, Canada, 2007.

2. Shanafelt T, Ripp J, Trockel M. Understanding and addressing sources of anxiety among health care professionals during the COVID-19 pandemic. JAMA. 2020;323:2133-2134.

3. Qiu J, Shen B, Zhao M, Wang Z, Xie B, Xu Y. A nationwide survey of psychological distress among Chinese people in the COVID-19 epidemic: implications and policy recommendations. Gen Psychiatr. 2020;33:e100213. Erratum in: Gen Psychiatr. 2020;33:e100213corr1.

4. Nikčević AV, Marino C, Kolubinski DC, Leach D, Spada MM. Modelling the contribution of the big five personality traits, health anxiety, and COVID-19 psychological distress to generalised anxiety and depressive symptoms during the COVID-19 pandemic. J Affect Disord. 2021;279:578-584.

5. Zhu Y, Zhang L, Zhou X, Li C, Yang D. The impact of social distancing during COVID-19: a conditional process model of negative emotions, alienation, affective disorders, and post-traumatic stress disorder. J Affect Disord. 2021;281:131-137. Erratum in: J Affect Disord. 2021;289:181.

6. Carvalho PMM, Moreira MM, de Oliveira MNA, Landim JMM, Neto MLR. The psychiatric impact of the novel coronavirus outbreak. Psychiatry Res. 2020;286:112902.

7. Brooks SK, Webster RK, Smith LE, Woodland L, Wessely S, Greenberg N, Rubin GJ. The psychological impact of quarantine and how to reduce it: rapid review of the evidence. Lancet. 2020;395:912-920.

8. Pietrabissa G, Simpson SG. Psychological consequences of social isolation during COVID-19 outbreak. Front Psychol. 2020;11:2201.

9. Bradburn NM. The structure of psychological well-being. 1969.

10. Kammann R, Flett R. Affectometer 2: a scale to measure current level of general happiness. Aust J Psychol. 1983;35:259-265.

11. Martin MM, Rubin RB. A new measure of cognitive flexibility. Psychol Rep. 1995;76:623-626.

12. Roothman B, Kirsten DK, Wissing MP. Gender differences in aspects of psychological well-being. S Afr J Psychol. 2003;33:212-218.

13. Karasar N. Bilimsel Araștırma Yöntemi. Ankara: Nobel Yayın Dağıtım. 2005;151.

14. Çiçek B, Almalı V. The relationship between anxiety self-efficacy and psychological well-being during COVID-19 pandemic process: comparison of private and public sector employees. Turkish Studies. 2020;15:241-260.

15. Diener E, Wirtz D, Biswas-Diener R, Tov W, Kim-Prieto C, Choi DW, Oishi S. New measures of well-being. Assessing well-being. Springer. 2009:247-266.

16. Yükseköğretim Kurumu, Yükseköğretim Bilgi Yönetim Sistemi. Available from: https://istatistik.yok.gov.tr/

17. Çalıkuşu M, Özçelikay G. Türkiye'de eczacılık mesleğinin gelecek işgücü kapasitesinin analizi. Eczacılıkta Yenilikler-3. 2020:145-156.

18. Yücenur GN, Demirel NÇ, Ceylan C, Demirel T. Measuring the effects of service value on behavioral intentions with a structural equation model. Doğuş Üniversitesi Dergisi. 2011;12:156-168.

19. Hair JF, Anderson RE, Tatham RL, Black WC. Multivariate Data Analysis with Readings. $4^{\text {th }}$ ed. Prentice-Hall International, Inc. 1995.

20. Liu C, Marchewka JT, Lu J, Yu CS. Beyond concern-a privacy-trustbehavioral intention model of electronic commerce. Inf Manag J. 2005;42:289-304. 
21. Wang S, Zhang Y, Ding W, Meng Y, Hu H, Liu Z, Zeng X, Wang $M$. Psychological distress and sleep problems when people are under interpersonal isolation during an epidemic: a nationwide multicenter cross-sectional study. Eur Psychiatry. 2020;63:e77.

22. Daly M, Robinson E. Psychological distress and adaptation to the COVID-19 crisis in the United States. J Psychiatr Res. 2021;136:603-609.

23. Lee SA, Crunk EA. Fear and psychopathology during the COVID-19 crisis: neuroticism, hypochondriasis, reassurance-seeking, and coronaphobia as fear factors. OMEGA: J Death Dying, 2022;85:483-496.

24. Lee SA, Mathis AA, Jobe MC, Pappalardo EA. Clinically significant fear and anxiety of COVID-19: a psychometric examination of the coronavirus anxiety scale. Psychiatry Res. 2020;290:113112.

25. Ye B, Wu D, Im H, Liu M, Wang X, Yang Q. Stressors of COVID-19 and stress consequences: the mediating role of rumination and the moderating role of psychological support. Child Youth Serv Rev. 2020;118:105466.

26. Shevlin M, McBride O, Murphy J, Miller JG, Hartman TK, Levita L, Mason L, Martinez AP, McKay R, Stocks TVA, Bennett KM, Hyland P, Karatzias T, Bentall RP. Anxiety, depression, traumatic stress and COVID-19-related anxiety in the UK general population during the COVID-19 pandemic. BJPsych Open. 2020;6:e125.

27. Joos A. Psychosomatic medicine and COVID-19 pandemic. Psychother Psychosom. 2020;89:263-264.

28. Duong CD. The impact of fear and anxiety of COVID-19 on life satisfaction: psychological distress and sleep disturbance as mediators. Pers Individ Differ. 2021;178:110869.

29. Casagrande M, Favieri F, Tambelli R, Forte G. The enemy who sealed the world: effects quarantine due to the COVID-19 on sleep quality, anxiety, and psychological distress in the Italian population. Sleep Med. 2020;75:12-20.

30. Ghasemi F. Zarei M, Heidarimoghadam R, Hosseini SM. Exploring unprecedented problems of academicians during the COVID 19 pandemic and their relationships with fatigue and mental health. Gene Reports. 2021;23:101098.

31. Rakhmanov O, Dane S. Knowledge and anxiety levels of African university students against COVID-19 during the pandemic outbreak by an online survey. J Med Dent Sci. 2020;8:53-56.

32. Tee ML, Tee CA, Anlacan JP, Aligam KJG, Reyes PWC, Kuruchittham V, Ho RC. Psychological impact of COVID-19 pandemic in the Philippines. J Affect Disord. 2020;277:379-391.

33. Hosseinzadeh-Shanjani Z, Hajimiri K, Rostami B, Ramazani S, Dadashi M. Stress, anxiety, and depression levels among healthcare staff during the COVID-19 epidemic. Basic Clin Neurosci. 2020;11:163-170.

34. Xu Y, Schneier F, Heimberg RG, Princisvalle K, Liebowitz MR, Wang S, Blanco C. Gender differences in social anxiety disorder: results from the national epidemiologic sample on alcohol and related conditions. J Anxiety Disord. 2012;26:12-19.

35. Asher M, Asnaani A, Aderka IM. Gender differences in social anxiety disorder: a review. Clin Psychol Rev. 2017;56:1-12.
36. McLean CP, Hope DA. Subjective anxiety and behavioral avoidance: gender, gender role, and perceived confirmability of self-report. J Anxiety Disord. 2010;24:494-502.

37. Gabster BP, van Daalen K, Dhatt R, Barry M. Challenges for the female academic during the COVID-19 pandemic. Lancet. 2020;395:1968-1970.

38. Lim GY, Tam WW, Lu Y, Ho CS, Zhang MW, Ho RC. Prevalence of depression in the community from 30 countries between 1994 and 2014. Sci Rep. 2018;8:2861.

39. Steel Z, Marnane C, Iranpour C, Chey T, Jackson JW, Patel V, Silove D. The global prevalence of common mental disorders: a systematic review and meta-analysis 1980-2013. Int J Epidemiol. 2014;43:476-493.

40. Wang C, Pan R, Wan X, Tan Y, Xu L, Ho CS, Ho RC. Immediate psychological responses and associated factors during the initial stage of the 2019 coronavirus disease (COVID-19) epidemic among the general population in China. Int J Environ Res Public Health. 2020;17:1729.

41. Le XTT, Dang AK, Toweh J, Nguyen QN, Le HT, Do TTT, Phan HBT, Nguyen TT, Pham QT, Ta NKT, Nguyen QT, Nguyen AN, Van Duong $Q$, Hoang MT, Pham HQ, Vu LG, Tran BX, Latkin CA, Ho CSH, Ho RCM. Evaluating the psychological impacts related to COVID-19 of Vietnamese people under the first nationwide partial lockdown in Vietnam. Front Psychiatry. 2020;11:824.

42. Marchetti D, Fontanesi L, Mazza C, Di Giandomenico S, Roma P, Verrocchio MC. Parenting-related exhaustion during the Italian COVID-19 lockdown. J Pediatr Psychol. 2020;45:1114-1123.

43. Kecojevic A, Basch CH, Sullivan M, Davi NK. The impact of the COVID-19 epidemic on mental health of undergraduate students in New Jersey, cross-sectional study. PLoS One. 2020;15:e0239696.

44. Cao W, Fang Z, Hou G, Han M, Xu X, Dong J, Zheng J. The psychological impact of the COVID-19 epidemic on college students in China. Psychiatry Res. 2020;287:112934.

45. Rehman U, Shahnawaz MG, Khan NH, Kharshiing KD, Khursheed M, Gupta K, Kashyap D, Uniyal R. Depression, anxiety and stress among Indians in times of COVID-19 lockdown. Community Ment Health J. 2021;57:42-48.

46. Fernández RS, Crivelli L, Guimet NM, Allegri RF, Pedreira ME. Psychological distress associated with COVID-19 quarantine: Latent profile analysis, outcome prediction and mediation analysis. J Affect Disord. 2020;277:75-84.

47. Ryff $C D$. Happiness is everything, or is it? Explorations on the meaning of psychological well-being. J Pers Soc Psychol. 1989;57:1069-1081.

48. Ryff $C D$, Keyes $C L$. The structure of psychological well-being revisited. J Pers Soc Psychol. 1995;69:719-727.

49. Gove WR, Hughes M, Style CB. Does marriage have positive effects on the psychological well-being of the individual? J Health Soc Behav. 1983;24:122-131. 